\title{
PENENTUAN AWAL WAKTU SUBUH MENGGUNAKAN SKY QUALITY METER PADA VARIASI DEKLINASI MATAHARI
}

\author{
Mustofa Ahyar $^{1}$, Yudhiakto Pramudya ${ }^{2}$, Abu Yazid Raisal ${ }^{3}$, Okimustava $^{4}$ \\ 1,2,3,4 Program Studi S2 Pendidikan Fisika, Pascasarjana Universitas Ahmad Dahlan, \\ Jl. Pramuka No. 42 Yogyakarta \\ Email : mustofaahyar1992@gmail.com
}

\begin{abstract}
Determination of the beginning of the prayer time is very important for Muslims, because it is one of the prayer pillars. However, the determination of beginning morning prayer is still difficult, because the sun is below horizon. The determination of beginning of dzuhur, ashr, and maghrib times are easier since sun's shadow is still clearly visible. The sun position is determined by sun declination. The sun declination value is given a positive sign (+) when it is north of the sky equator and negative sign (-) when it is to south of the celestial equator. This research method uses the experimental method. The determination of the subuh time has been done by measuring sky brightness level that was measured by SQM. There is a difference between the beginning of morning prayer time between the Accurate Times software calculation and the measurement. In the sun declination variation, difference data ranged from 21 - 36 minutes. From this study it was concluded that the value of sun declination affected the beginning of dawn time.
\end{abstract}

Keywords: dawn prayer, Sky Quality Meter, declination, Sky Brightness

\begin{abstract}
Abstrak: Penentuan awal waktu salat yang tepat penting bagi umat muslim, karena merupakan salah satu rukun salat. Namun, penentuan awal waktu salat subuh masih sulit, karena matahari berada di bawah horizon. Penentuan awal waktu zuhur, asar, dan magrib lebih mudah karena bayangan matahari masih terlihat jelas. Posisi matahari ditentukan oleh deklinasi matahari, nilai deklinasi matahari diberi tanda positif $(+)$ ketika berada di sebelah utara ekuator langit dan negatif (-) ketika berada di sebelah selatan ekuator langit. Metode penelitian ini menggunakan metode eksperimen. Penentuan awal waktu subuh dengan menggunakan pengukuran Tingkat Kecerahan Langit (TKL) ini diukur dengan Sky Quality Meter (SQM). Terdapat selisih awal waktu salat subuh antara perhitungan Software Accurate Times dan pengukuran. Pada variasi deklinasi matahari diperoleh data selisih berkisar antara 21-36 menit. Dari penelitian ini disimpulkan bahwa nilai deklinasi matahari berpengaruh terhadap awal waktu subuh.
\end{abstract}

Kata kunci: subuh, Sky Quality Meter, deklinasi, tingkat kecerahan langit

\section{PENDAHULUAN}

Penentuan waktu salat yang tepat adalah salah satu aspek penting dalam kehidupan seorang Muslim, karena merupakan salah satu rukun dalam ibadahnya agar diterima. Penentuan secara akurat waktu salat zuhur, asar dan magrib tidak terlalu sulit dikarenakan pergerakan matahari dapat diukur dengan panjang bayangan yang terlihat jelas. Namun, ada beberapa kesulitan dalam penentuan yang tepat untuk waktu salat subuh dan isya karena matahari berada dibawah horizon. Sehingga pengukuran bayangan tidak bisa ditampilkan (Raihana, 2016). Meskipun matahari berada dibawah horizon, namun terjadi perubahan pada Tingkat Kecerahan Langit (TKL). Semakin matahari berada jauh dibawah horizon, maka perubahan TKL tidak signifikan. Pengukuran TKL membutuhkan sensor cahaya yang sensitif, salah satunya dengan menggunakan SQM. 
Deklinasi matahari didefinisikan sebagai jarak matahari dari lingkaran ekuator diukur sepanjang lingkaran waktu yang melalui matahari itu hingga ke titik pusat matahari tersebut (Muhammadiyah, 2009). Deklinasi bernilai positif $(+)$ apabila matahari berada di sebelah utara ekuator. Sebaliknya, bernilai negatif (-) apabila matahari berada di sebelah selatan ekuator. Selain dalam penentuan waktu-waktu salat, data deklinasi juga diperlukan dalam penentuan bayang-bayang kiblat, waktu ijtimak, ketinggian hilal, gerhana, dan lain-lain (Butar-Butar, 2016). Penelitian tentang kecerahan langit malam untuk penentuan awal waktu subuh harus melalui pengamatan yang panjang dan pengambilan data melalui beberapa metode untuk memperkuat hasil peneltian. Sehingga dalam penelitian ini mengambil metode dengan deklinasi matahari, namun untuk diketahui sebelum penelitian ini sudah ada juga yang meneliti tentang awal waktu subuh dengan metode perbedaan fase bulan.

Hasil dari pengukuran tingkat kecerahan langit menggunakan SQM digunakan sebagai data pendukung untuk memverifikasi hisab salat ketika matahari tidak bisa diamati secara langsung karena matahari masih di bawah horizontal (Raisal, 2016)

\section{METODE PENELITIAN}

Metode penelitian ini menggunakan metode eksperimen. Pengambilan data dilakukan di beberapa lokasi dengan rentang waktu dari tahun 2016 hingga tahun 2018. Sebagian data menggunakan penelitian sebelumnya, namun berbeda analisisnya. Penelitian ini menggunakan alat dan prosedur sebagai berikut:

A. Alat

a. Unihedron Sky Quality Meter (SQM), merupakan sensor yang sangat berperan dalam penelitian ini untuk mengukur kecerahan langit.

b. Notebook, merupakan alat untuk mendapatkan dan memonitor pengambilan data serta untuk menganalisis data

c. Kabel Konektor, merupakan kabel penghubung antara sensor SQM dan notebook

d. Tripod, berfungsi sebagai penyangga sensor SQM

e. Kamera berfungsi untuk mendokumentasikan data visual ketika pangambilan data

f. Software:

- Accurate times 5.3, program penghitung waktu salat dengan operasi sistem Windows dibuat oleh Mohammad Odeh asal Yordania.

- Microsoft Excel 2013, program buatan Microsoft digunakan untuk menganalisis data dan membuat grafik.

- Stellarium, planetarium open source gratis dapat menampilkan langit secara 3D dengan mensetting titik koordinat terlebih dahulu.

- Unihedron Device Manager, aplikasi bawaan SQM untuk memproses data dari sensor ke notebook.

B. Prosedur Eksperimen

1. SQM dipasang ke tripod agar mudah dalam mengambil data dan diarahkan menghadap zenit.

2. SQM dihubungkan dengan notebook menggunakan kabel konektor.

3. SQM dijalankan menggunakan perangkat lunak Unihedron Device Manager dengan memilih log continuous. Pengambilan data setiap 5 detik.

4. Tombol record ditekan untuk mulai pengambilan data.

5. Dilakukan analsis data sebagai berikut:

a. Penentuan selisih awal waktu salat subuh

Setelah data berhasil diambil dan tersimpan dalam notebook, kemudian dianalisis dengan Software Microsoft Excel. Data yang diambil hanya beberapa dari data asli SQM. Setelah dianalisis akan didapatkan hasil Moving Average dan dicari angka nol (0) terakhir yang menunjukkan waktu subuh berdasarkan pengukuran SQM $\left(t_{u k u r}\right)$. Kemudian digunakan 
aplikasi Accurate Times untuk menentukan awal waktu subuh berdasarkan $\left(t_{\text {hitung }}\right)$. Selisih awal waktu subuh didapatkan dengan cara mengurangkan antara hasil pengukuran dan perhitungan, dan diambil nilai absolutnya dalam satuan menit.

$\Delta t=\left|t_{\text {hitung }}-t_{\text {ukur }}\right| \ldots \ldots \ldots \ldots \ldots \ldots \ldots \ldots \ldots$

b. Penentuan nilai deklinasi

Nilai deklinasi matahari dapat diketahui melalui software Stellarium. Dengan terlebih dahulu mencari matahari pada software dan menentukan waktunya, maka akan timbul data-data tentang matahari.

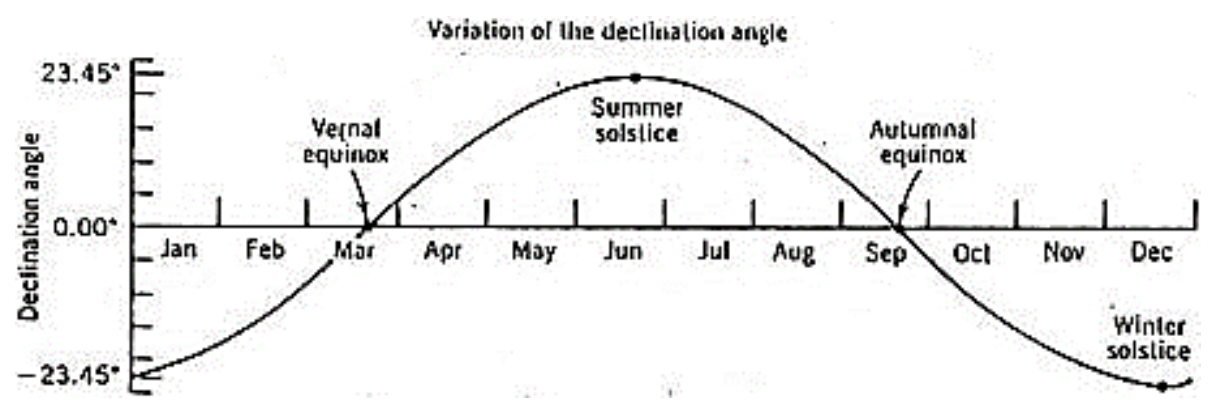

Gambar 1. Grafik deklinasi matahari terhadap waktu sepanjang tahun (http://www.reuk.co.uk, n.d.)

\section{HASIL DAN PEMBAHASAN}

Penelitian ini dilakukan di beberapa tempat berbeda dangan tingkat polusi yang berbeda pula, adapun lokasi tempat tersebut ditunjukkan pada tabel 1.

Tabel 2. Lokasi pengambilan data

\begin{tabular}{cl}
\hline Lokasi & \multicolumn{1}{c}{ Koordinat } \\
\hline $\mathbf{A}$ & $7^{\circ} 47^{\prime} 55.4^{\prime \prime} \mathrm{S} 110^{\circ} 23^{\prime} 02.4^{\prime \prime} \mathrm{E}$ \\
B & $7^{\circ} 48^{\prime} 39.3^{\prime \prime} \mathrm{S} 110^{\circ} 23^{\prime} 24.5^{\prime \prime} \mathrm{E}$ \\
$\mathbf{C}$ & $7^{\circ} 50^{\prime} 5.2^{\prime \prime} \mathrm{S} 110^{\circ} 23^{\prime} 0.4^{\prime \prime} \mathrm{E}$ \\
\hline
\end{tabular}

Selisih awal waktu salat subuh antara software Accurate Times dan sensor SQM pada variasi deklinasi matahari dari beberapa tempat ditunjukkan pada gambar. 


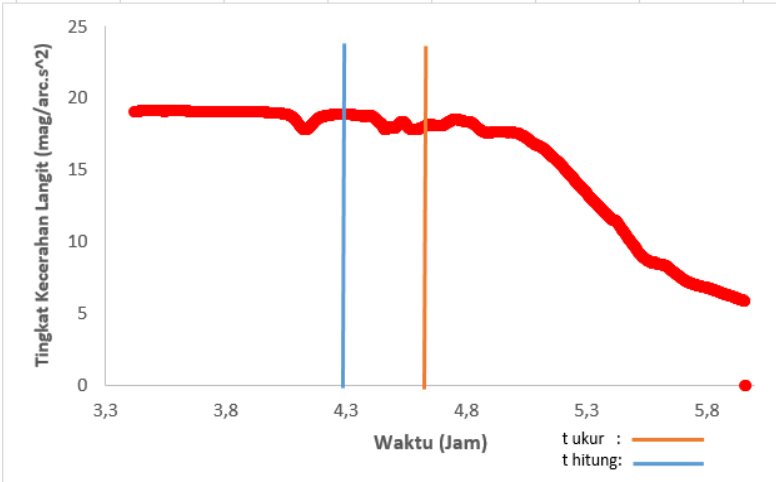

Gambar 2. Grafik selisih waktu subuh dan tingkat kecerahan langit pada lokasi A tanggal 11 Mei 2016

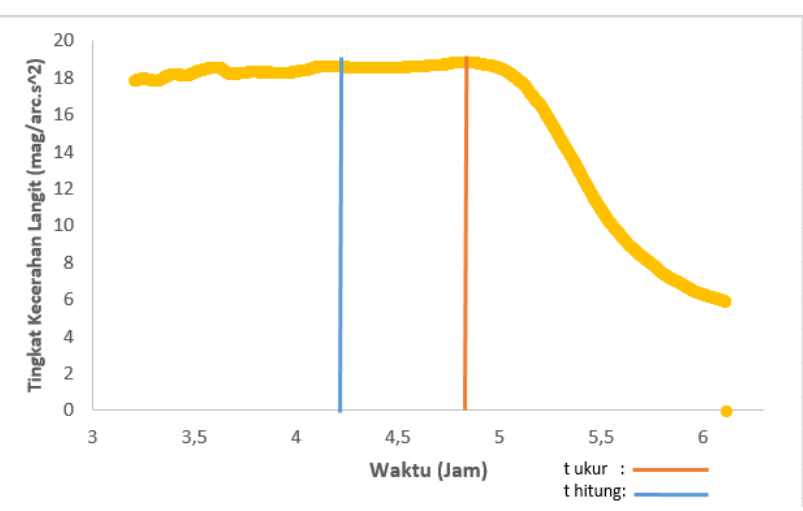

Gambar 3. Grafik selisih waktu subuh dan tingkat kecerahan langit pada lokasi B tanggal 24 Maret 2017

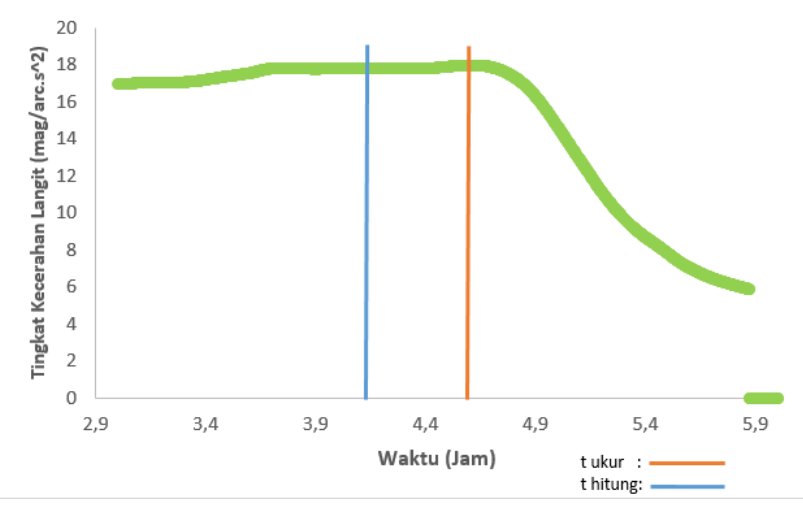

Gambar 4. Grafik selisih waktu subuh dan tingkat kecerahan langit pada lokasi C tanggal 03 Januari 2018 


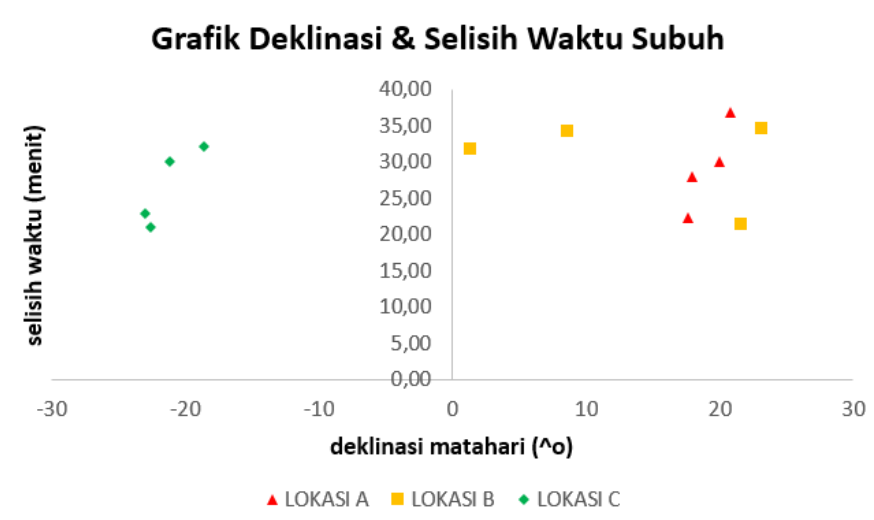

Gambar 5. Grafik deklinasi dan selisih waktu subuh dari beberapa tempat

Seperti yang ditunjukkan pada gambar 5, grafik menunjukkan menuju deklinasi rendah yang berpengaruh terhadap awal waktu subuh. Selisih waktu antara pengukuran SQM dan perhitungan Accurate Times berkisar antara 21 - 36 menit.

\section{KESIMPULAN}

Terdapat selisih waktu salat subuh antara sofware Accurate Times dan pengukuran menggunakan sensor SQM. Pada hasil pengukuran dengan SQM dan perhitungan dengan software Accurate Times diperoleh selisih awal waktu subuh berkisar antara 21 - 36 menit. Ini menunjukkan bahwa dari penelitian ini dapat disimpulkan nilai deklinasi matahari berpengaruh terhadap awal waktu subuh, selain nilai deklinasi, pengaruh cuaca dan permukaan tempat juga berperan. Perlu penenlitian lebih lanjut dengan data satu siklus matahari selama sebelas tahun untuk memperkuat teori.

\section{DAFTAR PUSTAKA}

AW. Raihana, K. N. (2016). Issues on Determination of Accurate Fajr and Dhuha Prayer Times According to Fiqh and Astronomical Perspective in Malysia: A Bibliography Study., (p. 675). Bali.

D. Herdiwijaya, S. N. (2011). Penentuan Waktu Gerhana Bulan Total 16 Juni 2011 Berdasarkan Sky Quality Meter. Prosiding Seminar Himpunan Astronomi Indonesia, 32.

Dr. H. Arwin Juli Rakhmadi Butar-Butar, M. (2016). Waktu Salat Menurut Fikih dan Astronomi. Medan: LPPM UMSU.

Herdiwijaya, D. (2016, september 7). Retrieved from Www.researchgate.net|https://www.researchgate.net/publication/307861438

Ismail. (2015). METODE PENENTUAN AWAL WAKTU SALAT DALAM PERSPEKTIF ILMU FALAK. ISLAM FUTURA, 87.

Mohammaddin Abdul Niri, M. Z. (2012). Astronomical Determinations for the Beginning Prayer Time of Isha. Middle-East Journal of Scientific Research, 103.

Muhammadiyah, M. T. (2009). Pedoman Hisab Muhammadiyah. Yogyakarta: Majelis Tarjih dan Tajdid Pimpinan Pusat Muhammadiyah.

Raisal A.Y, Pramudya Y.,. (2016). Analisis Awal Waktu Salat Subuh di Yogyakarta 
Berdasarkan Fase Bulan. Seminar Fisika.

Raisal A.Y, Pramudya Y., Okimustava, Muchlas(2017). The moonphases influence on the beginning of astronomical dawn determination in Yogyakarta. International Journal of Science and Applied Science: Conference Series.

Roderick, M. L. (1992). Methods for calculating solar position and day. Australia.

http://www.reuk.co.uk. 